\title{
A New Design of a Miniaturized UHF-RFID Passive Tag Antenna Based on L-Shape Radiators with Meandered Dipole
}

\author{
Yassine Gmih and Abdelmajid Farchi \\ \{yassine.gmih@gmail.com, abdelmajid.farchi1@gmail.com
}

Laboratory of Mechanical Engineering, Industrial Management and Innovation

University Hassan $1^{\text {st }}$, Faculty of Sciences and Technologies, Settat- Morocco

\begin{abstract}
This article suggests a simple and new miniaturized antenna for radio-frequency identification (RFID) tags in the European and Moroccan UHF band (866-869 MHz). Our structure consists of a meandering dipole, L-shaped radiators and a changed T-Match network. The meander technique was applied to decrease the antenna size; using this method, the size of our structure has been reduced to $68 \%$ compared to the classical UHF dipole. L-shaped radiators and a modified T-matching approach are also used to easily match the antenna input impedance to that of the chip to maximize power transfer. The size of our antenna is $50 \times 22 \mathrm{~mm}^{2}$, it has been designed on a single-sided FR-4 substrate with a thickness of $0.8 \mathrm{~mm}$ for a relative permittivity, $\mathrm{Er}$ of 4.4 . For our design, we chose the Higgs 4 IC chip (manufactured by Alien Technology, USA) which has an impedance of 20.5-j191 $\Omega$ obtained at the centre frequency $867 \mathrm{MHz}$. The antenna performance was studied with respect to the impedance matching, realized gain, reflection coefficients and read range of the label. Therefore, the proposed design achieved a gain of $1.2 \mathrm{~dB}$ and a maximum reading range of 13.94 meters at $867 \mathrm{MHz}$.
\end{abstract}

Keywords: Tag antenna; meander-line; T-Match; ultra-high frequency; radio frequency identification; L-Shape radiators; read range.

\section{Introduction}

Radio Frequency Identification or RFID is an emerging automatic identification technology that allows remote recognition, storage and retrieval of data from a target that contains personal data to be identified such as item price, date of manufacture, and ID number, etc. At present, it is receiving considerable international interest due to the growing technological support provided by a variety of RFID applications [1]. RFID systems are intended to operate in defined frequency bands, depending on the needs of the application and local radio frequency standards. Four principal frequency ranges exist: Low Frequency (LF: $125 \mathrm{KHz}$ ), High Frequency (HF: 13.56 MHz), Ultra-High Frequency (860-960 MHz), and Microwave band (2.45/5.8 GHz) [2], [3]. In particular, UHF passive RFID systems are very advantageously compared to regulate passive RFID systems [4] using low frequency and high frequency bands, as they can provide a greater and faster reading range and better information storage capacity [3]. Worldwide, the UHF band for RFID systems ranges from 860 to $960 \mathrm{MHz}$ where each country/region has a 
unique frequency band. For example, the band allocated to RFID applications in Europe is 866$869 \mathrm{MHz}$ and in North and in South and North America 902-928 MHz [5], [6].

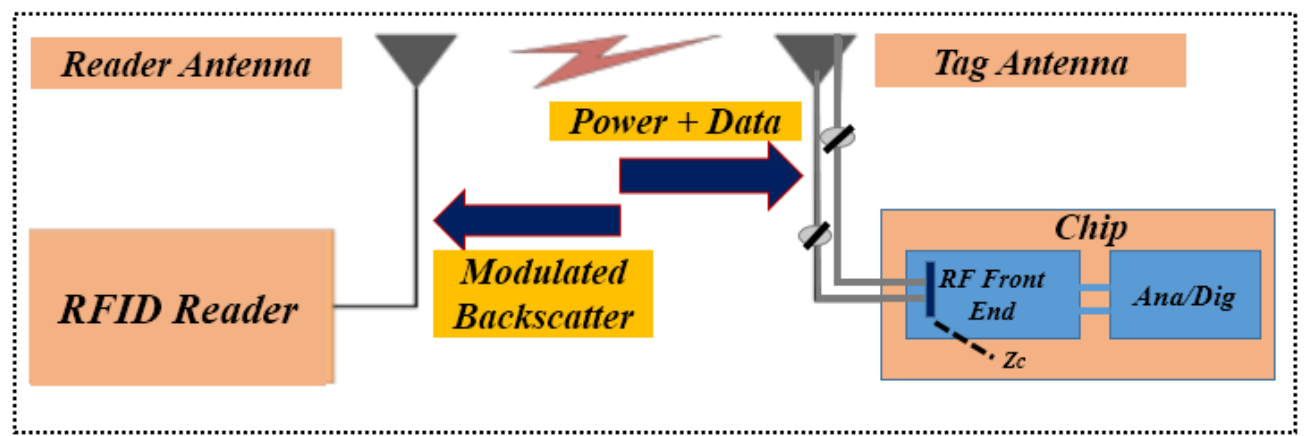

Fig. 1. RFID System Operation

A passive RFID system is composed of a tag that includes an antenna adapted to the ASIC chip (Application-Specific Integrated Circuit), a reader [7] and a personal computer to monitor the process. Figure 1 describes the functioning of a passive RFID system. In general, the chip impedance is capacitive, which requires that the antenna impedance be also inductive so as to get a proper impedance matching [8]. Several approaches are suggested in the scientific literature for impedance adaptation and miniaturization of the RFID tag antenna. The proposed feeding methods for adapting the antenna tag with the chip are T-match network, inductively coupled proximity loops, and the inclusion of nested or shaped slots [9-11]. For size reduction without significant trade-offs of tag performance, meander line structure by folding the arms of a dipole is utilized to increase the electrical length of the tag antenna [12-15], an inverted planar F antenna with a short-circuit pin used to reduce the size of a vertical wire monopole, and patch antenna with different shapes using slots on the design [16-19].

This study suggests a passive microstrip antenna with horizontal omnidirectional radiation pattern. The antenna works in the European UHF band (865-869 MHz). Its compact, low-profile structure makes it ideal for RFID applications. The antenna substrate used is an economical FR4 with a thickness of $0.8 \mathrm{~mm}$. The rectangular loop of the antenna is optimized to obtain a conjugated impedance matching of the microchip. The chosen chip for the proposed tag antenna is the Alien Higgs-4 SOT-323 type chip manufactured by Alien Technology, the USA [20]. The design of our antenna is small with overall dimensions of $50 \times 22 \mathrm{~mm}^{2}$. It is easy to design and manufacture thanks to its simple structure, without short-circuit pins or short-circuit plates.

The conjugate impedance matching and the read range of the antenna will be discussed in the following section, and Section III describes the antenna design and parametric study respectively. Section IV will present the performance of the tag and discuss the obtained results, and finally the conclusion and future work will be reported in section $\mathrm{V}$.

\section{Conjugate impedance matching method and read range}

Read range is the activation distance $d$ of the tag from the reader along the direction $(\theta, \varphi)$ [21] which is defined by the relationship (1) is generally performed in a controlled atmosphere like an anechoic chamber [12]. 


$$
\mathrm{d}=\frac{\lambda}{4 \pi} \cdot \sqrt{\frac{\mathrm{EIRP}_{\mathrm{R}} \cdot \tau \cdot \mathrm{Gt}}{\mathrm{Pc}}}
$$

EIRP $_{R}$ is the effective power transmitted by the reader (or EIRP $P_{R}=\operatorname{Pr} x$ Gr, where Pr is the power transmitted by the reader, and $\mathrm{Gr}$ is the gain of the emitting antenna), $\mathrm{Pc}$ is the sensitivity of the tag transponder, it is the minimum threshold power required to activate the chip and to perform back-scattering modulations, and Gt is the tag gain.

$$
\tau=1-[\Gamma]^{2}=\frac{4 \cdot \mathrm{R}_{\mathrm{ant}} \cdot \mathrm{R}_{\mathrm{ch}}}{\left|\mathrm{Z}_{\mathrm{ch}}+\mathrm{Z}_{\mathrm{ant}}\right|^{2}} \leq 1
$$

$\tau$ is the power transmission coefficient that is determined by the relationship (2), it is 0 to 1 , if it is 1 , which means that the impedance of the chip and antenna is perfectly matched, so the reading range of the labels will be maximal. $\Gamma$ (formula 3 ) is the reflection coefficient that takes into account the impedance difference between $Z_{\text {ant }}$ of the antenna and $Z_{c h}$ of the chip, with $Z_{\text {ant }}=$ $\mathrm{R}_{\mathrm{ant}}+\mathrm{j} \mathrm{X}_{\mathrm{ant}}$ and $\mathrm{Z}_{\mathrm{ch}}=\mathrm{R}_{\mathrm{ch}}+\mathrm{j} \mathrm{X}_{\mathrm{ch}}$ respectively [21].

$$
\Gamma=\frac{Z_{\mathrm{ch}}-Z_{\text {ant }}}{Z_{\mathrm{ch}}+Z_{\text {ant }}}
$$

$\mathrm{Z}_{\mathrm{ant}}$ is the input impedance of the antenna is given [22] by (4)

$$
Z_{\text {ant }}=R_{\text {ant }}+j X_{\text {ant }}=Z_{\text {loop }}+\frac{(2 \cdot \pi \cdot f \cdot M)^{2}}{Z_{m}}+Z_{L-\text { rad }}
$$

Where $Z_{\text {loop }}, Z_{\mathrm{m}}$ and $Z_{\mathrm{L}-\mathrm{rad}}$ are the respective personal impedances of the buckle, the meander lines and the L-shaped radiator, respectively. $\mathrm{M}$ is the reciprocal induction between the meander dipole and the loop.

The impedance of the chip is dependent on input power and frequency, because the transponder has an energy storage level, and its impedance is capacitive is not a direct transmission line $(50 \Omega)$, which requires that the antenna impedance be inductive to get an appropriate adaptation with that of the chip $\left(Z_{\mathrm{ch}}=20.5-\mathrm{j} 191 \Omega\right)$.

Above d, the power absorbed by the tag decreases below the sensitivity of the chip, making it even very hard to detect the RFID tag. In order to design a compact, low-cost label, the modified t-match network is used to adjust the antenna with chip, and a meander line technique is used to decrease the geometry of the label.

\section{Antenna design and parametric study}

Figure 2 illustrates the structure of the proposed miniaturized tag antenna with a total dimension $50 \times 22 \mathrm{~mm}^{2}(\mathrm{Ls} \times \mathrm{Ws})$ it was designed on a $0.8 \mathrm{~mm}$-thick (h) single layer FR-4 substrate (with relative permittivity, $\varepsilon r=4.4$ ) with copper thickness of $0.035 \mathrm{~mm}$ and loss tangent of 0.025 . Table 1 displays the parameters and the dimensions of the proposed tag 
antenna. Our antenna was designed and analysed using CST Microwave Studio software, v.15. It is composed of a meander-line dipole, and L-shaped radiators, and the modified T-match used to improve the impedance matching.

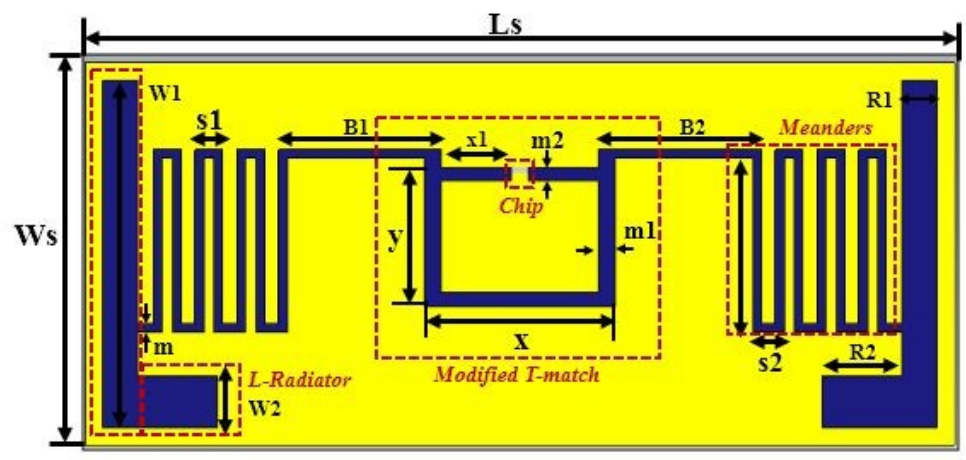

Fig.2. Geometry of the proposed antenna

Table 1. Dimensions of the proposed tag antenna

\begin{tabular}{cccc}
\hline Parameters & Values $(\mathrm{mm})$ & Parameters & Values $(\mathrm{mm})$ \\
\hline Ls & 50 & $\mathrm{~s} 2$ & 1.8 \\
Ws & 22 & $\mathrm{~m}$ & 0.5 \\
W1 & 20 & $\mathrm{~m} 1$ & 1 \\
W2 & 3 & $\mathrm{~m} 2$ & 0.8 \\
R1 & 2 & $\mathrm{x}$ & 11 \\
R2 & 4.6 & $\mathrm{x} 1$ & 4 \\
B1 & 9.4 & $\mathrm{y}$ & 8 \\
s1 & 1.6 & Gap & 1 \\
\hline
\end{tabular}

The equivalent circuit of our tag with a T-connection has been depicted in Figure 3 . The entire circuit model consists of the meander antenna, the matching T-circuit and the chip model. The Rs and Cs symbols represent the microchip input resistance and capacitance respectively. Our antenna is modelized like a resistor, inductor, capacitor (RLC) in series (Ra, La, Ca), which is cascaded with the adaptation part which has an adjustable reactance. Either parameter $\mathrm{x}$ indicates the inductance of shunt Ls and parameter $y$ indicates the serial inductance. By changing the length $\mathrm{x}$ and $\mathrm{y}$, the value of the shunt and the series inductance also vary [23].

The proposed tag is designed for the Higgs-4 EPC global class 1 Gen2 UHF RFID microchip fabricated by Alien Technology [20]. The chip packaging used in the design is SOT323. This type of packaging is easy to soldering manually. The most important advantage of using this chip is the minimum radio-frequency communication power that can reach the -18.5 $\mathrm{dBm}$ level. Thus, as a way of obtaining an RFID tag that can be identified at a short distance, a small antenna with a low gain can be employed. 


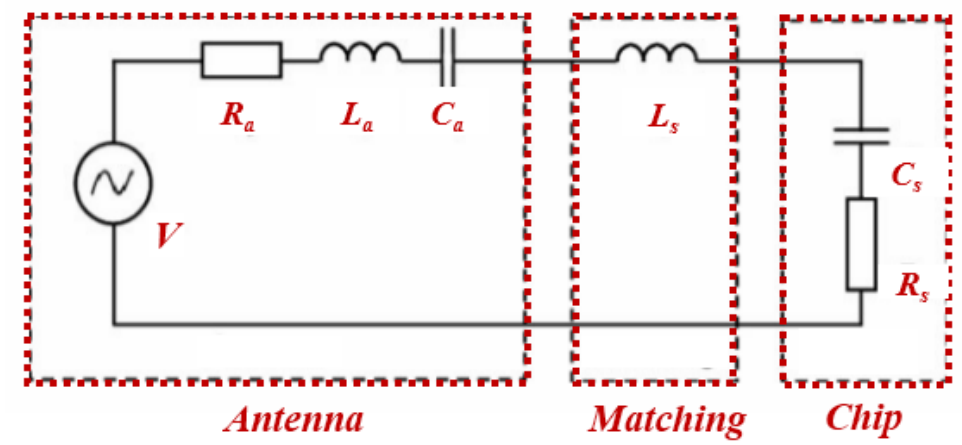

Fig.3. Equivalent circuit of tag antenna [2]

\subsection{Antenna with a different number of meander lines (n)}

In order to validate the design process, the tag antenna with a different number of meanders is modelled and simulated with CST-MS. $n$ represents the number of meanders. Figure 4 (a) displays the suggested tag with a different number of meanders with the same size. Figure 4 (b) depicts the antenna reflection coefficients when $\mathrm{n}=$ one, two, and three, respectively. It can be seen that the $-10 \mathrm{~dB}$ bandwidth ranges from $860-875 \mathrm{MHz}$, which covers the European RFID UHF band. When the number of meanders increases by increasing the total length of the halfwave dipole and always keeping the same total antenna size $\left(50 \times 22 \mathrm{~mm}^{2}\right)$, the resonance frequency shifts to the low frequencies. By using this method, the size of our antenna is decreased by up to $68 \%$ compared to the classical antenna.

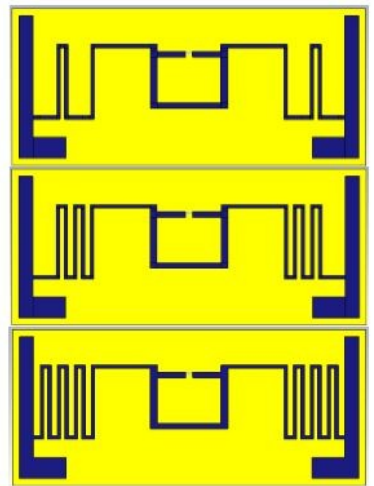

(a)

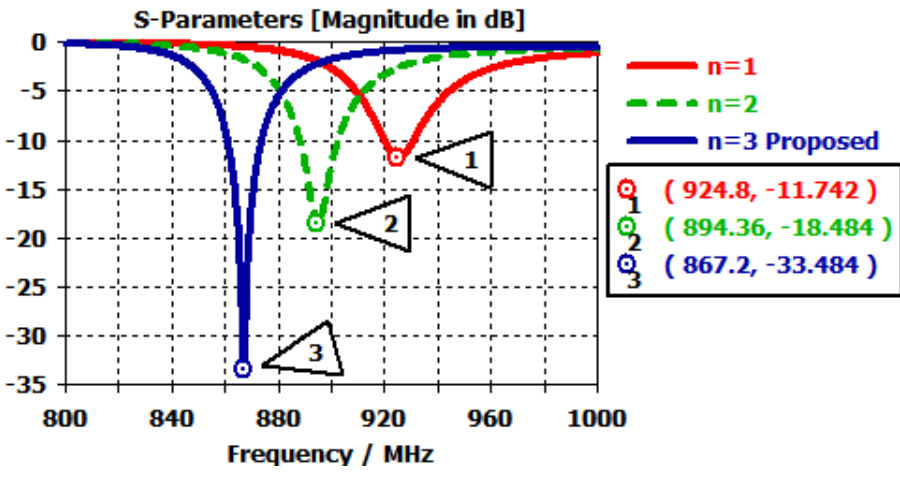

(b)

Fig.4. (a) The number of meanders $n$ is 1, 2, and 3, respectively, (b) Simulated reflection coefficients of tag antenna with different meanders 


\subsection{Antenna with varying loop sizes}

Figure 5 shows our design with different loop sizes when the number of meanders is fixed on three meanders $(\mathrm{n}=3)$. The antenna in the first case has a large loop with $\mathrm{x}=15 \mathrm{~mm}$ and $\mathrm{y}$ $=10 \mathrm{~mm}$. The second has a small loop with $\mathrm{x}=7 \mathrm{~mm}$ and $\mathrm{y}=6 \mathrm{~mm}$, and the optimized loop size for the proposed tag is $\mathrm{x}=11 \mathrm{~mm}$, with $\mathrm{y}=8 \mathrm{~mm}$. Figure 6 plots the input impedance characteristics ([a] real part and [b] imaginary part) of the tag. It is shown that if the horizontal $\mathrm{x}$ and vertical $\mathrm{y}$ of the T-matching rectangle (see Figure 1) are varied, the value of the shunt and inductance in series in the adaptation circuit changes. Therefore, the antenna and chip impedance can be easily adjusted both by changing the $\mathrm{x}$ and, $\mathrm{y}$ parameters, and therefore the impedance adaptation for the different chips can be easily obtained. In our case of the Higgs-4 chip, the optimal values for $\mathrm{x}$ and $\mathrm{y}$ are $11 \mathrm{~mm}$ and $8 \mathrm{~mm}$.

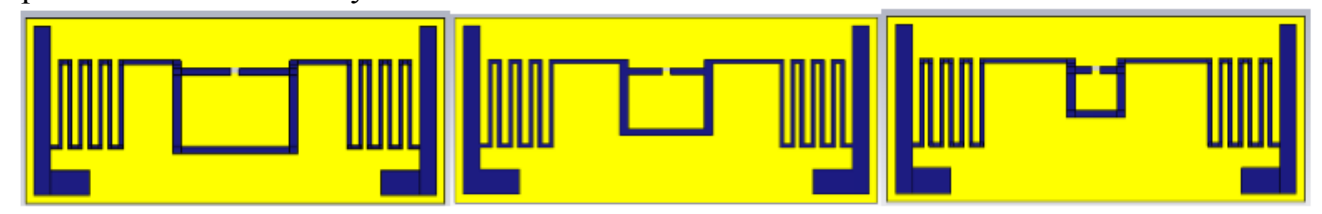

Fig.5. Tag antenna with different size of loop

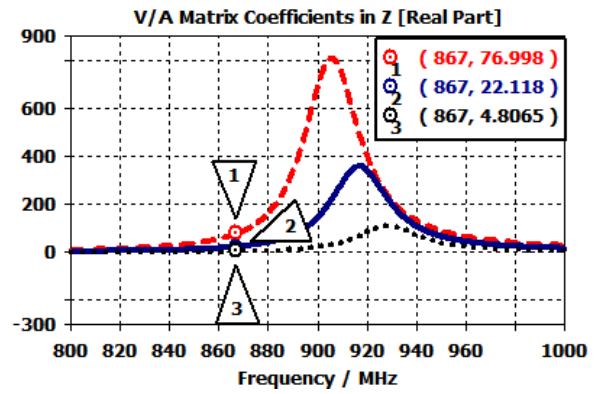

(a)

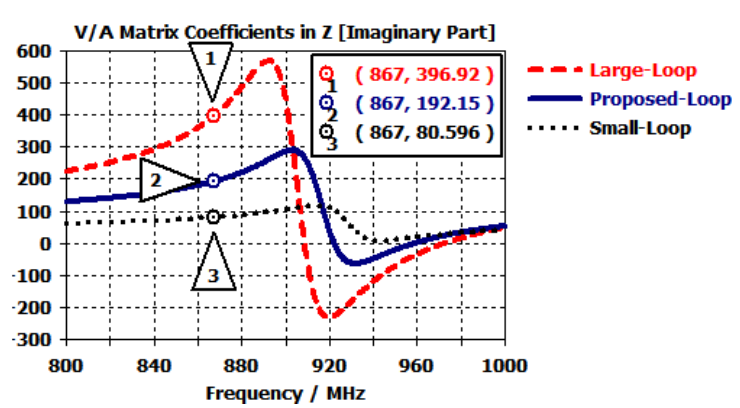

(b)

Fig.6. Simulated input impedance of tag antenna with different size of loop ((a) real and (b) imaginary part)

\subsection{Antenna with and without different radiator shape}

Figure 7 (b) depicts the reflection coefficients of our antenna with different shapes and without radiators, when the number of meanders is three. The first antenna has no radiator, and the second has an L-shaped radiator with a width of $\mathrm{R} 1=2 \mathrm{~mm}$, while our proposed label has an L-shaped radiator with a width of R2 $=4.6 \mathrm{~mm}$ in addition to R1 (see Figure 7 (a)). And since the shape of the radiator affects the impedance, the $S_{11}$ reflection coefficients can simply be controlled by varying the width of the radiator, which can be proven by Figure 7 (b). Noting that different resonance frequencies may also be achieved with different widths of R2. By increasing its value, the resonance frequency displaces itself to the lower frequency, with an improvement in impedance matching up to $-33.48 \mathrm{~dB}$ at the $867 \mathrm{MHz}$ center frequency. 


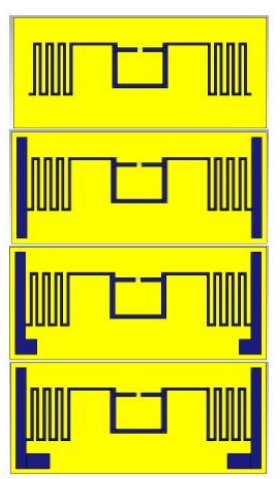

(a)

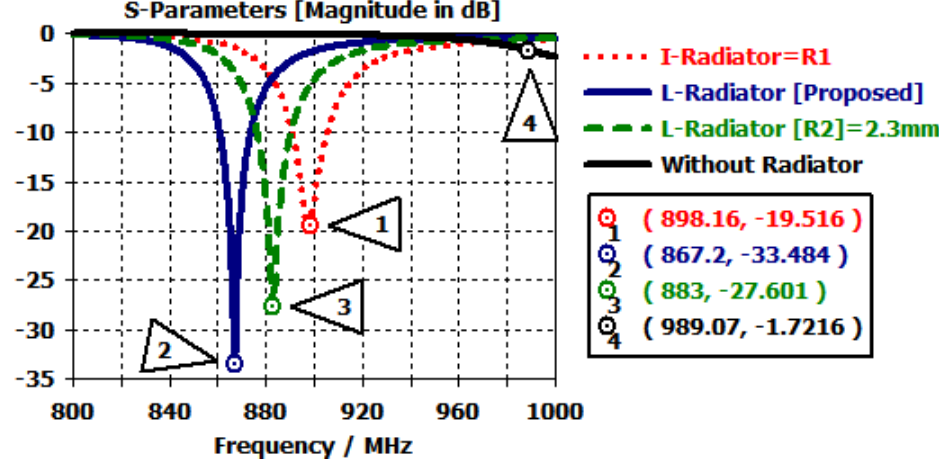

(b)

Fig.7. (a) Tag antenna with and without different radiator shapes (b) Simulated reflection coefficients of tag antenna with and without different radiator shapes

\section{Simulated results and discussions}

The proposed design is optimized using the CST-MS electromagnetic simulation software, which allows easy control of the antenna impedance matching. Figures 8 and 9 demonstrate the simulated reflection coefficient and impedance antenna of the proposed label. From the graphs, we can see that the reflection coefficient is $-33.48 \mathrm{~dB}$ and the antenna input impedance is equal to $Z_{\text {ant }}=22.1+\mathrm{j} 192.1 \Omega$ at $867 \mathrm{MHz}$, which is almost conjugated to the impedance of the chip $Z_{\mathrm{ch}}=20.5-\mathrm{j} 191 \Omega$, this correspondence can be verified and calculated with the formula (2) of $\tau$, we use this equation, we obtained a perfect power transfer coefficient equal to 0.98 ( $98 \%$ of the chip impedance). The antenna bandwidth is narrow but it covers the European band (866 - 869 $\mathrm{MHz}$ ). After all, we can see that our antenna has a perfect adaptation response to $867 \mathrm{MHz}$, the centre frequency of the ETSI (European Telecommunications Standards Institute) band.

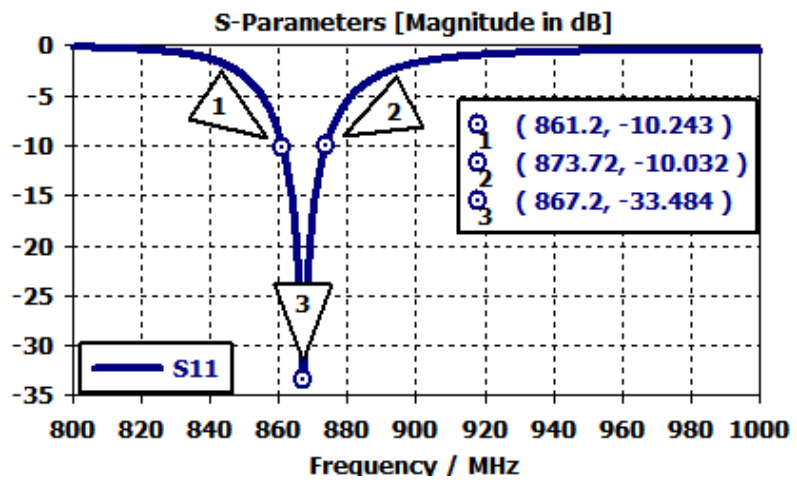

Fig.8. Simulated reflection coefficient of the proposed tag antenna 
Using formula (1), it is feasible to calculate the maximum distance at which the reader can detect the tag, with a minimum output power required for chip activation of $-18.5 \mathrm{dBm}$ and an effective isotropic radiated power $\left(\mathrm{EIRP}_{\mathrm{R}}\right)$ of the signal transmitted by the reader is 3.28 Watt in Europe. The maximum distance obtained by the suggested tag is 13.94 meters. Figure 10 (a) provides the polar radiation pattern of the label antenna. It has an omnidirectional radiation pattern in the $\mathrm{yz}$ - plane $(\mathrm{phi}=90)$ and a bidirectional radiation pattern in the $\mathrm{xz}$ - plane $(\mathrm{phi}=0)$ at in the $867 \mathrm{MHz}$ resonant frequency, which is desirable for RFID applications. The maximum gain achieved by the proposed tag is $1.2 \mathrm{~dB}$ at $867 \mathrm{MHz}$, as shown in Figure 10 (b).

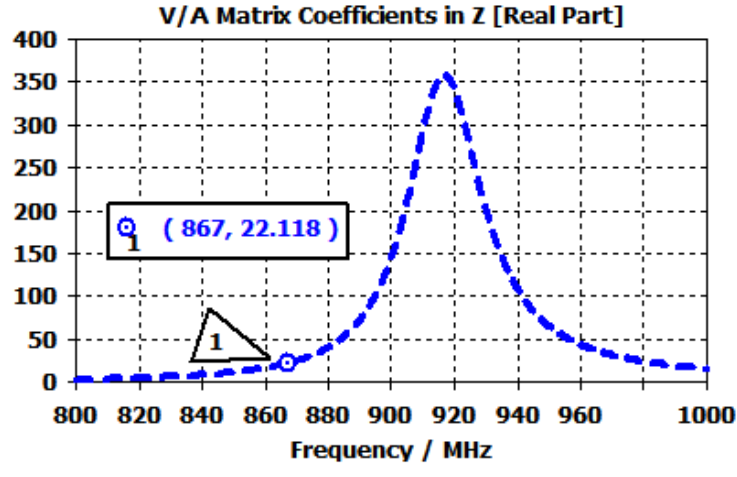

(a)

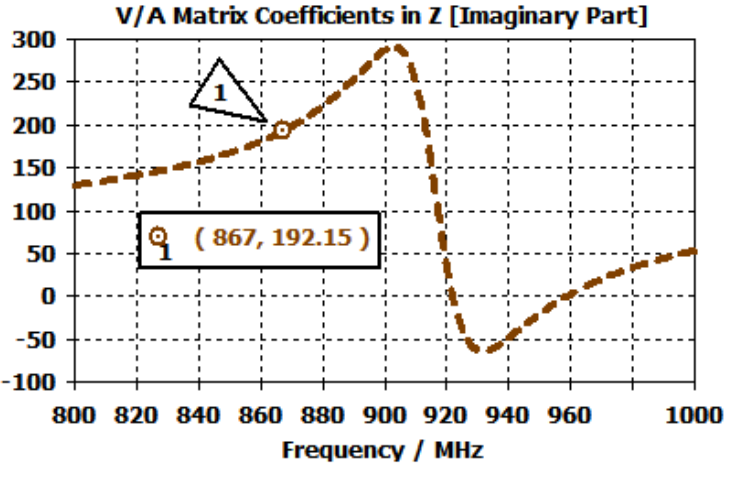

(b)

Fig.9. Simulated Input impedance of the proposed tag antenna ((a) real and (b) imaginary part)

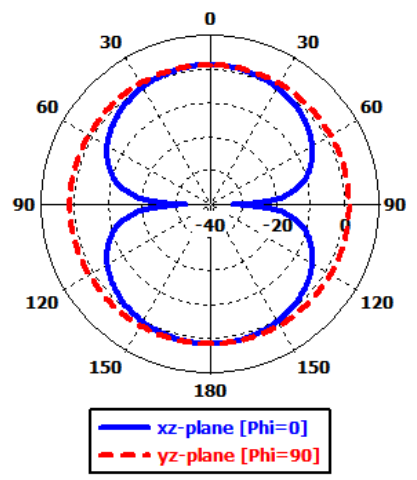

(a)

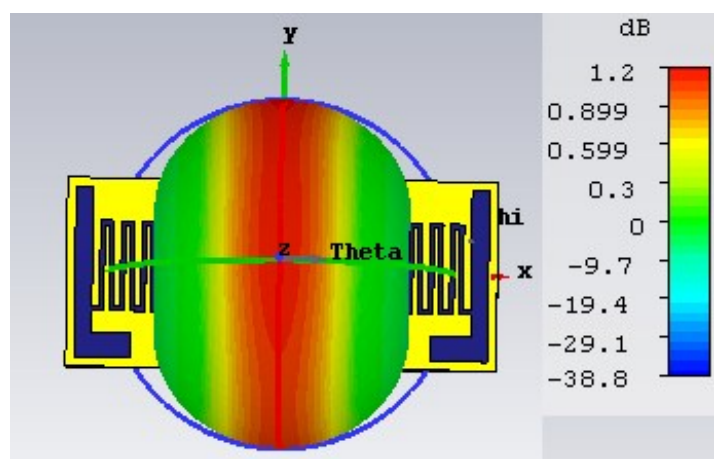

(b)

Fig. 10 (a) Polar radiation pattern of the proposed antenna (b) 3D realized gain

Table 2 compares the various antennas recently mentioned in published articles with our antenna in terms of total size, selected substrate and maximum reading range in free space. 
Table 2. Comparison of previous designs with the proposed antenna

\begin{tabular}{|c|c|c|c|c|}
\hline Design approach & Substrate & Frequency & Size $\left(\mathrm{mm}^{3}\right)$ & $\begin{array}{l}\text { Read range in } \\
\text { free space }\end{array}$ \\
\hline Loop feed meander-line antenna [24] & $\begin{array}{c}\text { Arlon foam clad (1 Er } \\
=1.1)\end{array}$ & $867 \mathrm{MHz}$ & $63.2 \times 21.9 \times 0.8$ & 5 meters \\
\hline Meander dipole tag antenna [25] & $\begin{array}{c}\text { Rogers } \mathrm{RT} / \text { duroid }(\mathrm{Er}= \\
2.2)\end{array}$ & 867.7 MHz & $77 \times 14 \times 0.787$ & 12.5 meters \\
\hline $\begin{array}{l}\text { Semi-circle looped with meander line } \\
\text { antenna [26] }\end{array}$ & FR4 $(E r=4.6)$ & $920 \mathrm{MHz}$ & $77.68 \times 35.5 \times 1.6$ & 8.3 meters \\
\hline Proposed antenna & FR4 $(\operatorname{Er}=4.4)$ & $867 \mathrm{MHz}$ & $50 \times 22 \times 0.8$ & 13.94 meters \\
\hline
\end{tabular}

Based on the reported work on the design and implementation of the RFID tag for the UHF band, the overall antenna size in this study is the smallest of the tag antennas reported in the comparison. Additionally to its small size, our antenna offers a large maximum reading range of 13.94 meters in free space, making it a good candidate for RFID applications that require a large distance to identify it. The concept used to design compact labels, as described in the preceding section, may also be implemented on other flexible substrates for RFID identification.

\section{Conclusion}

A new miniaturized meandered line tag antenna in European and Moroccan band is proposed in this paper. The antenna is composed of copper layer traces and one-sided FR4 substrate with the dimension of $50 \times 22 \times 0.8 \mathrm{~mm}^{3}$. The label antenna is designed to be matched to the conjugated impedance of the UHF Higgs-4 RFID chip which has an impedance of 20.5j191 $\Omega$. The proposed tag antenna design includes meander line, L-shaped radiators and modified T-match technique for size reduction and impedance matching respectively. The antenna does not have a short circuit plate or through hole, which makes it easier to manufacture's. The simulation results demonstrate that the impedance matching performance of the proposed tag is satisfactory at $867 \mathrm{MHz}$. In addition to this, our antenna has an omnidirectional radiation pattern with a reading range of 13.94 meters, which proves that the label antenna is a great candidate for a compact and low-power consumption system of passive RFID tags. The proposed design of the tag antenna is tested by simulation and will be manufactured and measured in the near future.

\section{References}

[1] Chawla, V., Dong-Sam, H.: An overview of passive RFID. Communications Magazine, IEEE. Vol. 45, n9, pp 7-11 (2007)

[2] Dobkin, D. M.: The RF in RFID: Passive UHF RFID in Practice. USA (2008)

[3] Finkenzeller, K.: RFID Handbook: Radio-Frequency Identification Fundamentals and Applications. Wiley, Second Ed. New York, USA (2004)

[4] El Hachimi,Y., Gmih, Y., Makroum, M., and Farchi, A.: A Miniaturized Patch Antenna Designed and Manufactured Using Slot's Technique for RFID UHF Mobile Applications. Int. J. of Electrical and Computer Engineering (IJECE). Vol. 8, No. 6, pp. 5134-5143 (2018) 
[5] MingYin, L., RongLin L.: A Low Profile Broadband RFID Tag Antenna for Metallic Objects. International Conference on Microwave and Millimeter Wave Technology. pp. 1891-1893 (2010).

[6] Bhatt, H.and Grover, B.: RFID Essentials. OReilly Media, Inc. (2006)

[7] El Hachimi,Y., Gmih, Y., Makroum, M., and Farchi, A.: Miniature RFID Antenna at UHF Band using Meander-Line Technique. Int. J. of Electrical and Computer Engineering (IJECE). Vol. 8, No. 4, pp. 2280-289 (2018)

[8] Zamora, G., Zuffanelli, S., Paredes, F., Martın, F., and Bonache, J.: Design and Synthesis Methodology for UHF-RFID Tags Based on the T-Match Network. IEEE Transactions on Microwave Theory and Techniques. pp. 4090-4098, Vol. 61, n. 12, (2013)

[9] Marrocco, G.: The art of UHF-RFID antenna design: impedance matching and size-reduction techniques. IEEE Antennas Propag. Mag. Vol. 50, n. 1, pp. 66-79 (2008)

[10] Pumpoung, T.; Wongsiritorn, P.; Phongcharoenpanich, C.; Kosulvit, S.: Characteristics of a meander line tag antenna with T-Loop structure for the passive UHF RFID applications. In Proc. IEEE Int. Conf., Electron Devices and Solid State Circuit. pp. 1-4 (2012)

[11] Choo, J., J. Ryoo, and al.: T-matching networks for the efficient matching of practical RFID tags. European Microwave Conference (EuMC). Rome, Italy. pp. 5-8 (2009).

[12] Seshagiri Rao, K.V., and Nikitin, P.V.: Antenna design for UHF RFID tags: a review and practical application. IEEE Trans. Antennas Propag. Vol. 53 n. 12, pp 3870-3876 (2005)

[13] Ma, Z.L., Jiang, L.J., Xi, J., Ye, and T.T.: A compact HF/UHF dual band RFID tag antenna. In Proc. IEEE Antennas and Propagation Society Int. Symp. pp. 1122-1123 (2013)

[14] Liu, Q.; Shen, J.; Liu, H.; Wu, Y.; Su, M.; Liu, Y.: Low-cost compact circularly polarized directional antenna for universal UHF RFID handheld reader applications. IEEE Antennas Wireless Propag. Lett. Vol. 14, pp. 1326-1329 (2015)

[15] Hirvonen, M.; Pursula, P.; Jaakkola, K.; Laukkanen, K.: Planar inverted-F antenna for radio frequency identification. Electron. Lett. Vol. 40 (14), pp. 848-850 (2004)

[16] Deleruyelle, T., Pannier, P.: Multi-standard slot antenna in 860-960 MHz and $2.45 \mathrm{GHz}$ RFID band. In Proc. Antennas and Propagation Society Int. Symp. IEEE. pp. 1-4 (2008)

[17] Santiago, A.G., Costa, J.R., and Fernandes C.A.: Broadband UHF RFID passive tag antenna for near-body applications. IEEE Antennas Wireless Propag. Lett. Vol. 12, pp. 136-139 (2013)

[18] Svanda, M., Polivka, M.: Matching technique for an on-body low- profile coupled patches UHF RFID tag and for sensor antennas. IEEE Trans. Antennas Propag. Vol. 63 (5), pp. 2295-2301 (2015)

[19] Mirchandani, P.; Deshpande, K.; Khan, R.: Performance analysis of miniaturized microstrip patch antennas for UHF RFID applications. In Proc. Int. IEEE Conf. Signal Processing, Comm., Computing and Networking Technologies. pp. 244-249 (2011)

[20] Higgs 4 IC Datasheet. An EPCglobal Complaint Class-1 Gen-2 ISO/IEC 18000-6C UHF RFID Integrated Circuit, Alien Technology (2017)

[21] Zhang, J., and Long, Y.: A dual-layer broadband compact UHF RFID tag antenna for platform tolerant application. IEEE Tran. On Antennas and Propagation. Vol. 61, no. 9, pp. 4447-4455 (2013)

[22] Choi, W., Son, H. W., Shin, C., Bae, J., and Choi, G.: RFID tag antenna with a meandered dipole and inductively coupled feed. IEEE Antennas and Propagation Society International Symposium. pp. 619-622 (2006)

[23] Tsai, M.-C., Chiu, C.-W., Wang, H.-C., and Wu, T.-F.: Inductively coupled loop antenna design for UHF RFID on Body applications. Progress in Elect. Research, Vol. 143, pp. 315-330 (2013).

[24] Ma, Y., Abd-Alhameed, R. A., Zhou, A., See, C.H., Abidin, Z.Z., Jin, C., and, Peng, B.: Loop feed meander-line antenna RFID tag design for UHF band. Proc. General Assembly and Scientific Symp. pp. 1-4 (2014)

[25] Dhaoudi, M., Mabrouk, M., Vuong, T.P., De Souza, A.C., and Ghazel, A.: A broadband UHF tag antenna for near-field and far-field RFID communications. Radio Eng., Vol.23 (4), 1026-1032 (2014) [26] Rokunuzzaman, Md., Islam, M. T., Rowe, W. S. T., Kibria, S., Singh, M. J., and Misran, N.: Design of a Miniaturized Meandered Line Antenna for UHF RFID Tags. Public Library of Science (Plos One), 17 August (2016) 